\begin{tabular}{|c|c|c|}
\hline $\begin{array}{l}\text { Erin A. Dean, MD } \\
\text { Staff Physician, Department of Psychiatry } \\
\text { and Psychology, Cleveland Clinic, } \\
\text { Cleveland, } \mathrm{OH}\end{array}$ & $\begin{array}{l}\text { Michelle Biehl, MD } \\
\text { Staff Physician, Pulmonary and Critical Care } \\
\text { Medicine; Director, Post-ICU Recovery Clinic } \\
\text { (PIRC), Cleveland Clinic, Cleveland, OH }\end{array}$ & $\begin{array}{l}\text { Kathryn Bash, APRN, CNP } \\
\text { Pulmonary and Critical Care Medicine, } \\
\text { Cleveland Clinic, Cleveland, } \mathrm{OH}\end{array}$ \\
\hline $\begin{array}{l}\text { Jeremy Weleff, DO } \\
\text { PGY4, Department of Psychiatryand Psycholo } \\
\text { Cleveland Clinic, Cleveland, } \mathrm{OH}\end{array}$ & \multicolumn{2}{|c|}{$\begin{array}{l}\text { Leopoldo Pozuelo, MD } \\
\text { Chair, Department of Psychiatry and Psychology; } \\
\text { Fellowship Director, Consultation-Liaison } \\
\text { Pyschiatry; Staff Consultant, Department of } \\
\text { Cardiovascular Medicine, Cleveland Clinic, } \\
\text { Cleveland, OH }\end{array}$} \\
\hline
\end{tabular}

\title{
Neuropsychiatric assessment and management of the ICU survivor
}

\section{ABSTRACT}

Any survivor among the millions of patients admitted to the intensive care unit (ICU) for critical illness each year is susceptible to persistent health problems that continue after discharge and may lead to post-intensive care syndrome (PICS), defined as new or worsening dysfunction from physical impairment, cognitive impairment, or emotional impairment, or a combination. Considering the increased rates of ICU survival and the growing elderly population more likely to utilize ICU resources, critical care practitioners have broadened their focus on outcomes and care of ICU survivors to include the acute post-ICU survival period as well as months and even years after ICU discharge. This review focuses on the neuropsychiatric aspects of PICS in ICU survivors including diagnostic, screening, and treatment recommendations. It also highlights the value of post-ICU clinics and the unique role of the consultation psychiatrist in the care of this patient population.

\section{KEY POINTS}

From $50 \%$ to $70 \%$ of the millions of patients admitted to the ICU each year will experience PICS, defined as new or worsening dysfunction in one or more of the following domains: physical impairment, cognitive impairment, and emotional impairment.

Critical care practitioners have broadened their focus of post-ICU care to include more than just the typical acute post-ICU care of 30 days after discharge.

To help navigate post-ICU care for survivors, post-ICU clinics have been developed where ICU survivors can receive outpatient follow-up care from a multidisciplinary team of providers to address their targeted needs. illions of patients are admitted to the inV tensive care unit (ICU) annually in the United States. ${ }^{1}$ The most frequent diagnoses associated with ICU admissions include the following:

- Respiratory failure including acute respiratory distress syndrome (ARDS)

- Acute myocardial infarction

- Cerebral infarction

- Percutaneous cardiovascular procedures

- Severe sepsis or septic shock. ${ }^{1}$

Considering the increased rates of ICU survival (currently $71 \%$ to $90 \%)^{1}$ and the growing elderly population (20\% of the global population will be over age 65 by 2050), ${ }^{2}$ more people are likely to utilize ICU resources.

Any survivor of a critical illness and ICU stay is susceptible to health problems that continue to persist after discharge and may lead to post-intensive care syndrome (PICS). PICS was designated as a syndrome by the Society of Critical Care Medicine in 2010, ${ }^{3}$ occurs in 50\% to $70 \%$ of ICU survivors, ${ }^{4}$ and is defined as new or worsening dysfunction in one or more of the following domains: physical impairment, cognitive impairment, and emotional impairment. We will explore each of these domains through a psychiatric lens.

As a result, critical care practitioners have broadened their focus on outcomes and care of ICU survivors to include the acute post-ICU survival period (30 days after ICU discharge) as well as the months and even years after ICU discharge. Post-ICU recovery care is even more necessary during the COVID-19 pandemic as early studies noted ICU admission rates of $32 \%$ of all COVID-19 patients, ${ }^{5,6}$ increasing the number of ICU survivors in need of care.

This review focuses on neuropsychiatric 
aspects of care of ICU survivors, particularly regarding symptoms associated with PICS including neuropsychiatric diagnostic, screening, and treatment recommendations, as well as the value of post-ICU recovery clinics.

\section{POST-INTENSIVE CARE SYNDROME}

\section{Physical impairment}

ICU-acquired weakness can be categorized as critical illness polyneuropathy, critical illness myopathy, and critical illness neuropathy and myopathy. It may affect up to half of ICU survivors admitted for 1 week or more. ${ }^{1}$ Specifically, about two-thirds of mechanically ventilated patients, $60 \%$ of patients with adult respiratory distress syndrome, and half of patients with sepsis will experience some degree of ICU-acquired weakness. ${ }^{7,8}$

Several aspects of critical illness contribute to ICU-acquired weakness, from the cellular level (mitochondrial dysfunction, release of inflammatory cytokines) to systemic concerns such as inactivity and malnutrition. ${ }^{2}$ Patients with ICU-acquired weakness who also have comorbid cognitive or emotional dysfunction may be less able to participate in physical rehabilitation and other therapies to improve weakness, thus placing them at further risk of prolonged physical weakness and highlighting the importance of targeted prevention and intervention for overall mental and physical recovery.

Other important aspects of physical morbidity are exercise limitation, fatigue, joint immobility, impairment of activities of daily living, shortness of breath, hair loss, voice changes, dysphagia, and sexual dysfunction. ${ }^{9-11}$ All of these impairments may affect quality of life and can subsequently interfere with the mental health of ICU survivors.

\section{Cognitive impairment}

ICU survivors are at risk of acute and chronic cognitive dysfunction. ${ }^{12-18}$ From $20 \%$ to $40 \%$ of ICU survivors experience persistent cognitive impairment, an undeniable major complication of critical illness that most commonly affects cognitive areas of executive function, attention, and memory. ${ }^{12}$ Cognitive dysfunction in ICU survivors has been associated with decreased quality of life, even in patients who recover physically. ${ }^{19}$ Some patients with persistent cognitive impairment are no longer able to work. Studies have shown that $30 \%$ to $38 \%$ of patients were able to return to work 3 months after ICU discharge. ${ }^{13-15}$ At 12 months post-ICU, $42 \%$ to $58 \%$ of patients were able to return to work. ${ }^{13,16-18}$ Depending on the severity of the cognitive impairment, patients' family members are sometimes obligated to forfeit their social and occupational roles and adopt a new role of caregiver; this can be a significant financial burden for patients and families and also has societal impact considering substantial productivity loss. ${ }^{4}$

Delirium. Delirium is a well-known cognitive complication of ICU admission, affecting up to $75 \%$ of ICU patients with an increased incidence in mechanically ventilated patients. ${ }^{20}$ Pandharipande et $\mathrm{a}^{20}$ noted a longer duration of delirium to be associated with worse global cognition and executive function at 3 and 12 months and with worsening depressive symptoms and quality of life 1 year after ICU discharge. Pathophysiologic causes of delirium include acute inflammatory responses, metabolic derangements-particularly hyperglycemia and hormonal disturbances, and toxic or medication-induced delirium from exposure to benzodiazepines, opiates, sedatives, hypnotics, steroids, and anticholinergic medications. ${ }^{12}$

Delirium is not always associated with persistent cognitive impairment as many patients recover cognitive function with treatment of their underlying medical conditions. However, Gunther et al linked delirium duration to brain changes in patients admitted to the ICU with respiratory failure or shock. ${ }^{21}$ Longer delirium duration was independently associated with smaller overall brain volumes on magnetic resonance imaging (MRI) as well as smaller superior frontal lobe volumes at hospital discharge and 3-month follow-up. Significantly smaller hippocampal volumes were noted at time of discharge in patients with increased delirium duration; these differences were statistically significant, but there was not a statistically significant difference at 3-month follow-up. Serial MRI studies have shown decreased thalamic and cerebellar volumes at 3-month follow-up in patients with longer periods of hospital delirium that were associated with worse executive functioning 
and visual attention impairment at 12 months post-ICU. ${ }^{21}$

Delirium in COVID-19 patients. Delirium has been identified in $10 \%$ to $30 \%$ of COVID-19 hospitalized patients. ${ }^{22,23}$ The incidence of delirium that can present even in the absence of respiratory symptoms in $\mathrm{CO}$ VID-19 ICU patients is not precisely known, but estimates range from $50 \%$ to $80 \% \cdot{ }^{24,25}$ Furthermore, management of delirium associated with COVID-19 involves a step-based pharmacologic intervention protocol established by Massachusetts General Hospital with a graduated progression from melatonin, to alpha-2 agonists, to low-potency antipsychotics, to valproic acid and dopamine agonists. ${ }^{26}$

Delirium risk factors. There are several nonmodifiable pre-ICU risk factors for delirium including older age, lower level of education, pre-existing cognitive impairment, acute severity of illness, and presence of the apolipoprotein E epsilon 4 allele or major genetic risk factor for Alzheimer disease (even in the absence of major neurocognitive disorder). ${ }^{12}$ Thus, practitioners need to identify and implement prevention strategies for potentially modifiable risk factors for delirium including sleep hygiene, frequent reorientation, assurance that sensory augmentation devices are provided (eyeglasses, hearing aids), avoidance of deliriogenic medications (narcotics, hypnotics, anticholinergics), metabolic and hemodynamic stability, and appropriate sedation weaning. Delirium prevention is reviewed later in this article including the use of the Society of Critical Care Medicine ICU Liberation Bundle (A-F). ${ }^{27,28}$

\section{Emotional impairment}

Up to one-third of ICU survivors may experience a range of psychiatric dysfunctions after discharge. ${ }^{29}$ Patients with emotional impairment related to PICS are more likely to experience decreased quality of life. ${ }^{29}$ For the purpose of this article, emotional impairment encompasses psychiatric, psychological, and mental health symptoms.

Depression. Post-ICU depression affects about $30 \%$ of ICU survivors and is associated with increased medical admissions and emergency department visits. ${ }^{30}$ Of note, patients with post-ICU depression more often report somatic symptoms (fatigue, decreased physical energy, psychomotor slowing) rather than cognitive-affective symptoms. These symptoms can be difficult to differentiate from physical symptoms of critical illness. Somatic symptoms of depression are less likely to respond to antidepressant medications and may require more comprehensive treatment strategies. ${ }^{30}$ The BRAIN-ICU study reported that severe depressive symptoms in the early post-ICU period (first 3 months) were likely to persist as $33 \%$ of the study population experienced at least mild depressive symptoms at 3-month follow-up that continued at 12-month follow-up. ${ }^{31}$

Anxiety. The prevalence of anxiety in ICU survivors is estimated to be about $70 \%{ }^{4}$ Patients with post-ICU anxiety often have comorbid post-ICU depression or post-traumatic stress disorder (PTSD) ${ }^{29}$ As previously noted, patients who report anxiety after ICU admission also report decreased quality of life. Many patients with post-ICU anxiety had anxiety symptoms that persisted 12 months after discharge. ${ }^{29}$

Post-traumatic stress disorder. PTSD prevalence after ICU care ranges from 10\% to $50 \%{ }^{32,33}$ Davydow et $\mathrm{al}^{33}$ reported that $40 \%$ of ICU survivors developed clinically significant symptoms of avoidance and hyperarousal, occurring twice as frequently as intrusion symptoms (nightmares and flashbacks); this is crucial for accurate assessment of post-ICU trauma symptoms. ${ }^{34}$ It is important to ask patients if they are avoiding medical appointments, taking alternate routes to avoid driving by hospitals or their doctor's office, or feeling constantly "on guard" since hospitalization. These post-ICU PTSD symptoms also lower health-related quality of life. ${ }^{35}$

Predictors of post-ICU PTSD include psychopathology (particularly PTSD or depression) prior to hospitalization and greater ICU benzodiazepine use. ${ }^{32,33}$ Interestingly, there is a greater risk of PTSD symptoms with higher total benzodiazepine dose rather than prolonged benzodiazepine duration. ${ }^{35}$ Finally, post-ICU memories of frightening or psychotic ICU experiences are risk factors. ${ }^{32,33}$ In examining post-ICU PTSD, mechanical ventilation use or duration of use, ICU length of stay, and ICU admission diagnosis have not been

\section{Care of ICU survivors now includes the acute post-ICU period, as well as months and even years after ICU discharge}




\section{TABLE 1}

\section{Screening instruments for post-intensive care unit cognitive impairment}

\begin{tabular}{|c|c|c|c|}
\hline Screening tool & $\begin{array}{l}\text { Number } \\
\text { of questions }\end{array}$ & Interpretation of results & Further information \\
\hline \multirow[t]{4}{*}{$\begin{array}{l}\text { Montreal Cognitive } \\
\text { Assessment (MoCA) }\end{array}$} & \multirow[t]{4}{*}{30} & $\begin{array}{l}\text { 26-30 Normal cognitive function } \\
<26 \text { Ninety percent sensitive for mild cogni- }\end{array}$ & \multirow{4}{*}{$\begin{array}{l}\text { Promising, larger studies needed for } \\
\text { validation in critical illness patients } \\
\text { Excellent reliability independent of } \\
\text { intensive care unit setting }\end{array}$} \\
\hline & & $\begin{array}{l}<26 \text { Ninety percent sensitive for mild cogni- } \\
\text { tive impairment and } 100 \% \text { sensitive for } \\
\text { dementia of Alzheimer (although scores for } \\
\text { Alzheimer disease are typically much lower) }\end{array}$ & \\
\hline & & $\begin{array}{l}\leq 18 \text { Cutoff typically used for dementia of } \\
\text { Alzheimer }\end{array}$ & \\
\hline & & $\begin{array}{l}\text { Note: If patient has } \leq 12 \text { years of education, } \\
\text { add } 1 \text { point to score }\end{array}$ & \\
\hline \multirow{2}{*}{$\begin{array}{l}\text { MoCA-blind (MoCA } \\
\text { without visual } \\
\text { elements) }\end{array}$} & \multirow[t]{2}{*}{22} & $\geq 18$ No cognitive impairment & \multirow{2}{*}{$\begin{array}{l}\text { Scoring is only suggestive and has not } \\
\text { been validated }\end{array}$} \\
\hline & & $\leq 17$ Suggestive of cognitive impairment & \\
\hline \multirow{4}{*}{$\begin{array}{l}\text { Mini-Mental State } \\
\text { Examination }\end{array}$} & \multirow[t]{4}{*}{30} & 24-30 No cognitive impairment & \multirow{4}{*}{$\begin{array}{l}\text { Poor sensitivity in survivors of acute } \\
\text { respiratory illness }\end{array}$} \\
\hline & & 18-23 Mild cognitive impairment & \\
\hline & & 0-17 Severe cognitive impairment & \\
\hline & & Note: Ranges may vary based on education level & \\
\hline
\end{tabular}

Based on information in references $40-44$

shown to be significant risk factors. There is mixed evidence on whether delirium is a risk factor for post-ICU PTSD. ${ }^{32,33}$

Substance abuse. Post-ICU substance abuse has not been well studied. It is known that alcohol use disorders are independent risk factors for the development of critical illness ${ }^{36}$ and are associated with an increased risk of mortality in critically ill patients. ${ }^{37}$ However, there are minimal data outlining alcohol use disorders before and after ICU admission. In examining alcohol use in patients at the time of critical illness and up to 12 months after ICU discharge, ${ }^{38}$ Davydow et al found a significant decrease in alcohol use from the period just before critical illness to 3 months after ICU discharge. This is not atypical as patients tend to make healthier lifestyle choices and avoid harmful behaviors after critical illness. However, alcohol use significantly increased from $3.8 \%$ of the study population at 3 months to $7.5 \%$ at 12 months after ICU discharge. ${ }^{38}$ Many patients with post-ICU alcohol abuse also had unhealthy alcohol use in the year before ICU admission: $80 \%$ and $67 \%$ of patients with unhealthy alcohol use at 3-month and 12-month follow-up, respectively, exhibited unhealthy alcohol use in the year prior to ICU admission. ${ }^{38}$

\section{ASSESSMENT AND SCREENING}

Several screening tools are used to identify the different aspects of PICS, thereby complicating result comparisons. ${ }^{39-44}$ Turnbull et $\mathrm{al}^{39}$ examined 425 studies and found 250 instruments used for different measures of ICU survivorship, including physical limitations, cognitive limitations, mental health limitations, participation restrictions, and quality of life. Needham et $\mathrm{al}^{40}$ aimed to minimize heterogeneity through the Core Outcome Measurement Set with the objective of developing a core set of measurement tools for use in all clinical research of acute respiratory failure survivors after hospital discharge (including acute respiratory distress syndrome). Although identification of these measurement tools is a significant advance in consistency 


\section{TABLE 2}

\section{Screening instruments for post-intensive care unit emotional impairment}

\begin{tabular}{|c|c|c|c|}
\hline Screening tool & Number of questions & Interpretation of results & Further information \\
\hline \multicolumn{4}{|l|}{ Depression } \\
\hline $\begin{array}{l}\text { Hospital Anxiety and Depression } \\
\text { Scale (HADS) }\end{array}$ & $\begin{array}{l}14 \text { total, } 7 \text { focusing on } \\
\text { depression symptoms }\end{array}$ & $\begin{array}{l}0-7 \text { Normal } \\
8-10 \text { Borderline abnormal (borderline case) } \\
11-21 \text { Abnormal }\end{array}$ & Validated in ICU population \\
\hline $\begin{array}{l}\text { Hamilton Depression Rating } \\
\text { Scale (HAM-D) }\end{array}$ & $\begin{array}{l}21 \text { items, scoring based } \\
\text { on first } 17 \text { items }\end{array}$ & $\begin{array}{l}\text { 10-13 Mild } \\
14-17 \text { Mild to moderate } \\
>17 \text { Moderate to severe }\end{array}$ & \\
\hline Beck Depression Inventory-II & $\begin{array}{l}21 \text { items (13-item } \\
\text { short-form available) }\end{array}$ & $\begin{array}{l}\text { 0-14 Minimal } \\
\text { 14-19 Mild } \\
\text { 20-28 Moderate } \\
\geq 29 \text { Severe }\end{array}$ & \\
\hline $\begin{array}{l}\text { Patient Health Questionnaire-9 } \\
\text { (PHQ-9) }\end{array}$ & 9 & $\begin{array}{l}\text { 1-4 Minimal } \\
\text { 5-9 Mild } \\
\text { 10-14 Moderate } \\
\text { 15-19 Moderately severe } \\
\text { 20-27 Severe }\end{array}$ & \\
\hline
\end{tabular}

Anxiety

\begin{tabular}{|c|c|c|c|}
\hline $\begin{array}{l}\text { Hospital Anxiety and Depression } \\
\text { Scale (HADS) }\end{array}$ & $\begin{array}{l}14 \text { total, } 7 \text { focusing on } \\
\text { depression symptoms }\end{array}$ & $\begin{array}{l}0-7 \text { Normal } \\
8-10 \text { Borderline abnormal } \\
11-21 \text { Abnormal }\end{array}$ & Validated in ICU population \\
\hline $\begin{array}{l}\text { Hamilton Anxiety Rating Scale } \\
\text { (HAM-A) }\end{array}$ & 14 & $\begin{array}{l}\text { 0-13 Minimal } \\
\text { 14-17 Mild } \\
\text { 18-24 Moderate } \\
\text { 25-30 Severe }\end{array}$ & \\
\hline $\begin{array}{l}\text { Generalized Anxiety Disorder } \\
\text { 7-item (GAD-7) }\end{array}$ & 7 & $\begin{array}{l}\text { 0-4 Minimal } \\
5-9 \text { Mild } \\
\text { 10-14 Moderate } \\
15-21 \text { Severe }\end{array}$ & \\
\hline
\end{tabular}

\section{PTSD}

Impact Event Scale-Revised (IES-R) (abbreviated IES-R)

Posttraumatic Symptom Scale, 10 items (PTSS-10)

10

PTSD Checklist for DSM-5

(PCL-5)

20

Abbreviated Posttraumatic Checklist (PCL-C)
24-32 Clinical concern for PTSD

33-38 Clinical cutoff for probable PTSD diagnosis $\geq 39$ Significant enough symptoms to suppress immune system (even 10 years after impact event)

Calculated as mean of 6 questions with higher scores representing more-severe PTSD symptoms

Cutoff score $\geq 35$ predicts PTSD (PTSS-High)

Total score of 31-33 or higher suggests patient may benefit from PTSD treatment

$\geq 14$ suggestive of difficulties with posttraumatic stress
Validated in ICU population

Validated in ARDS survivors ${ }^{47}$

Validated in ICU population

Good reliability

Detects PTSD symptoms

but does not diagnose PTSD

ARDS = acute respiratory distress syndrome; DSM = Diagnostic and Statistical Manual of Mental Disorders; ICU = intensive care unit; PTSD = posttraumatic stress disorder Based on information in references 5, 40, and 45-47. 


\section{TABLE 3}

\section{The ICU Liberation Bundle (A-F)}

A: Assessment, prevention, and management of pain

B: Both spontaneous breathing trials and spontaneous awakening trials

C: Choice of analgesia and sedation

D: Delirium: assessment, prevention, and management

E: Early mobilization and exercise

F: Family engagement and empowerment

Adapted from information in references 27,28 , and 48

in clinical research of symptoms of critically ill patients who have been discharged, caution should be used when implementing these tools in the general ICU survivor population as the study focused only on patients with acute respiratory failure.

\section{Screening tools}

Table $1^{40-44}$ presents screening tools most commonly used for cognitive impairment in PICS patients. Needham et $\mathrm{al}^{40}$ noted that for the "cognitive" outcome group in acute

PTSD prevalence after ICU care ranges from $10 \%$ to $50 \%$ respiratory failure survivors, no instrument reached a priori for consensus; however, the highest rated tool was the Montreal Cognitive Assessment (MoCA-Blind), used to screen patients for neurocognitive symptoms in the post-ICU period. It has been shown to be a reliable screening tool independent of being used for patients who were hospitalized or in the ICU. ${ }^{41}$ MoCA-Blind uses a cutoff score of 26 to differentiate between normal cognitive function and cognitive impairment; these cutoffs have been found to differ based on patient race and ethnicity. ${ }^{42} \mathrm{It}$ has been recommended to use the traditional MoCA-Blind, excluding the areas with visual elements (visuospatial, executive functioning, and naming portions) to facilitate administering the instrument by phone if needed. The Mini-Mental State Examination (MMSE) has been shown to be a poor measure of cognitive deficits in survivors of acute respiratory failure ${ }^{43}$ and may underestimate the degree of cognitive impairment compared with other assessment tools that focus on specific cognitive domains. ${ }^{44}$
Table $2^{5,40,45-47}$ lists commonly used tools for measuring post-ICU emotional dysfunction, including the Hospital Anxiety and Depression Scale (HADS) for detection of anxiety and depression symptoms ${ }^{45}$ and the Impact Event Scale-Revised (IES-R) ${ }^{46}$ for assessment of PTSD symptoms. Both the HADS and IES$\mathrm{R}$ have been recommended as core outcome measurement sets by Needham et al. ${ }^{40}$ From a psychiatric perspective, the Patient Health Questionnaire-9 (PHQ-9) is used to screen for depression while the Generalized Anxiety Disorder-7 (GAD-7) is used to screen for anxiety, and the Impact Event Scale-Revised (IES-R) is used to screen for PTSD.

\section{INTERVENTIONS}

There are several intervention strategies for management of cognitive and emotional disturbances. While some treatments are for specific post-ICU impairments, many are useful in managing symptoms spanning multiple domains of PICS. Many critical care units have adopted the ICU Liberation Bundle (Table 3) to prevent delirium, prolonged cognitive impairment, and significant post-ICU psychiatric symptoms. ${ }^{27,28,48}$ For example, dexmedetomidine has been associated with a lower incidence of delirium compared with other analgesia and sedative agents. ${ }^{49}$

\section{COGNITIVE REHABILITATION}

Prolonged post-ICU cognitive impairment may warrant further investigation. Physical, cognitive, and vocational rehabilitation have been studied in patients with ongoing cognitive dysfunction. ${ }^{31,49,50}$ In the Returning to Everyday Tasks Utilizing Rehabilitation Networks study, ${ }^{50}$ cognitive rehabilitation was delivered in the patient's home once every 2 weeks over a 12 -week study period. ICU survivors suffering from post-ICU cognitive impairment who received post-discharge cognitive rehabilitation in addition to "usual" post-discharge care (physical rehabilitation, occupational rehabilitation, nursing care) showed improvement in cognitive function at 3-month follow-up compared with patients who did not undergo cognitive rehabilitation. ${ }^{50}$ Given variability of cognitive interventions and studied populations, evidence-based 
recommendations for clinical practice are difficult to determine. There are promising data for the role of aerobic exercise in improving post-ICU cognitive function, ${ }^{12}$ and neurocognitive testing has been employed for patients with prolonged cognitive impairment. ${ }^{51}$ However, barriers to assessing cognitive function and thereby providing care to this population include social stigmatization and financial strain, loss of patients to follow-up, and patient frustration over testing performance. ${ }^{51}$ Of note, there are limited data on the role of these strategies in preventing prolonged cognitive impairment in critical care patients.

\section{MEDICATIONS}

Few studies have investigated pharmacologic treatments for cognitive impairment in ICU survivors specifically. Current strategies are from studies of cognitive impairment treatment in patients with traumatic brain injury. Methylphenidate and donepezil have been studied in the traumatic brain injury population and were associated with improvement in memory and attention. ${ }^{52-54}$ Although these strategies may be considered for ICU survivors with cognitive impairment, they should be implemented cautiously as further investigation is warranted for the critical care population specifically. ${ }^{49}$ Rosuvastatin was studied in the prevention of delirium and cognitive impairment in ICU patients but was not found to have significant benefit in prevention. ${ }^{55}$

\section{PSYCHOTHERAPY}

Psychotherapy may be beneficial for psychiatric symptom management in ICU survivors. The patient's presenting psychiatric symptoms may guide the type of therapy recommended. For example, some patients with mild depression, anxiety, or PTSD symptoms may benefit from supportive therapy. Moderate to severe mood and anxiety symptoms may respond more appropriately to cognitive behavioral therapy, while patients with more advanced trauma symptoms may benefit from traumabased therapy, including but not limited to eye-movement desensitization and reprocessing, a form of psychotherapy that allows patients to access and process traumatic memories through simultaneous focus on external stimuli such as eye movement. Haerizadeh et al reviewed psychological treatment modalities for PTSD in medically ill patients. ${ }^{56} \mathrm{Al}$ though limited data were available, 2 of the included trials showed exposure-based cognitive behavioral therapy resulted in a lower incidence of PTSD symptoms compared with control groups. And 3 trials included found eye-movement desensitization and reprocessing to be more effective in reducing PTSD symptoms than relaxation therapy, imaginal exposure, and conventional cognitive behavioral therapy. ${ }^{56}$

Patients with more severe psychiatric symptoms may warrant pharmacologic management. There is a lack of literature analyzing pharmacologic treatment for depression, anxiety, and PTSD in ICU survivors. It is important to note that ICU survivors warrant ongoing monitoring by a primary care provider or mental health clinician as they may be more sensitive to medication side effects given their underlying medical comorbidities and potential risk of drug interactions with other medications.

\section{ICU DIARIES}

ICU diaries are used to fill memory gaps for ICU survivors and provide an understanding of ICU events in a chronologic or narrative account. ${ }^{57}$ The diaries are often completed by ICU staff including physicians, advanced practice providers, nurses, consultants, and other providers involved in ICU patient care (eg, physical therapists, occupational therapists, music therapists, art therapists). Families may also participate in construction and completion of the ICU diaries.

ICU diaries have been increasingly used as a management strategy for emotional disturbances of PICS in ICU survivors. Data analyzing effects of ICU diaries on psychiatric symptoms in ICU survivors have been mixed. Barreto et $\mathrm{al}^{57}$ found that the use of ICU diaries was associated with decreased rates of depressive symptoms and depression diagnoses, mostly beneficial in ameliorating anxiety symptoms, but did not significantly improve PTSD symptoms. Garrouste-Orgeas et $\mathrm{al}^{58}$ found no statistically significant benefit in reduction of PTSD symptoms from use of
Post-ICU recovery clinics provide targeted outpatient follow-up care 


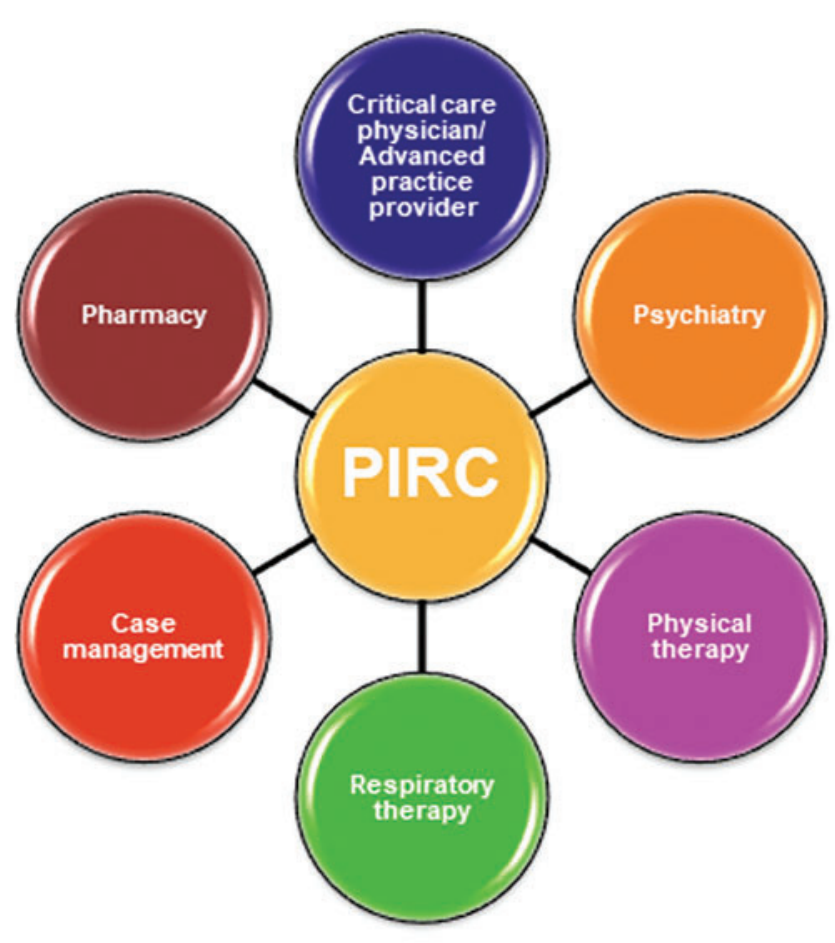

Figure 1. The multidisciplinary team approach used in the Cleveland Clinic Post-ICU Recovery Clinic (PIRC).

Neuro-

psychiatric

symptoms

are prevalent

and at times

disabling

in ICU survivors
ICU diaries in mechanically-ventilated ICU patients at 3 -month follow-up. ${ }^{58}$

Of note, there is no universal template for ICU diaries. This unstructured document is used by the patient and, after discharge, also by the family if the patient so chooses.

\section{THE ROLE OF POST-ICU RECOVERY CLINICS}

PICS symptoms after ICU stays led to a reevaluation of methods of care. Traditionally, within 1 month of hospital discharge, ICU survivors would have a brief follow-up visit with their primary care provider to address the complexities of a potentially extended critical care hospitalization. However, the time constraints of a brief office visit increased the risk that the patient's complex post-discharge needs would be suboptimally addressed.

Recognizing these issues, critical care providers have developed post-ICU recovery clinics where ICU survivors can receive outpatient follow-up care targeted to their needs. These clinics are composed of multidisciplinary teams usually including but not limited to critical care specialists, physical therapists, case managers, social workers, re- spiratory therapists, pharmacists, and mental healthcare professionals such as psychiatrists and psychologists.

Reported outcomes of post-ICU clinics have been positive overall in improving depression, anxiety, and PTSD symptoms..$^{59,60}$ Also, qualitative outcomes have revealed positive results for patients and families, who reported higher levels of satisfaction from involvement in these clinics. ${ }^{60}$

The Post-ICU Recovery Clinic (PIRC) at Cleveland Clinic (Figure 1) involves an ICU physician, ICU advanced practice provider, pharmacist, physical therapist, respiratory therapist, and mental health providers. $\mathrm{Pa}$ tients are triaged as they are discharged from the ICU based on inclusion and exclusion criteria found in Table 4. The patients that meet inclusion criteria are tracked while on the regular nursing floor to capture discharge disposition; patients discharged to skilled nursing facilities are not eligible for the clinic. The PIRC project manager consults with the patient to discuss PICS and the PIRC. If the patient voices interest, a post-discharge PIRC visit is scheduled. The goal is to see patients in the clinic within 4 weeks after hospital discharge.

During the post-discharge PIRC visit, several screening tools (Tables 1 and 2) are used to determine the patient's level of physical, cognitive, and emotional impairment. Based on the patient's symptom severity on screening tools and during personal interviews, a referral may be made to a clinical psychologist for psychotherapy or to a consultation psychiatrist for medication management. If patients show cognitive impairment based on screening or are reporting significant cognitive dysfunction compared with their pre-ICU baseline, a referral is made to neuropsychiatry for further symptom management.

\section{IMPORTANT CHANGES TO MEET A PRESSING NEED}

Neuropsychiatric symptoms are prevalent and at times disabling in ICU survivors. Previously, survivors have been at increased risk of psychiatric symptoms going undetected owing to limitations in post-discharge follow-up, mental health stigma, and limitations in financial 


\title{
TABLE 4
}

\section{Cleveland Clinic Post-ICU Recovery Clinic: Inclusion and exclusion criteria}

\author{
Inclusion criteria Shock (requiring vasopressor support) \\ Acute respiratory distress syndrome \\ Mechanical ventilation $\geq 3$ days \\ Prolonged intensive care unit (ICU) stay ( $\geq 7$ days) \\ Delirium present during intensive care unit stay \\ Cardiac arrest \\ COVID-19 with intensive care unit stay $>48$ hours
}

\begin{tabular}{l}
\hline Exclusion criteria \\
Discharged to skilled nursing facility \\
Significant cognitive impairment \\
Long-term mechanical ventilation before intensive care unit \\
admission (eg, for chronic respiratory failure)
\end{tabular}

and social circumstances due in part to acute and chronic medical conditions. ICU survivor neuropsychiatry is an emerging field that continues to be evaluated and is even more pressing in the COVID-19 era.

Clinicians seeing patients in the ICU and in the outpatient setting should be knowledgeable about the potential for PICS and appropriate screening tools for patient monitoring. Even with advances made in identifying screening tools in ICU respiratory survivors, further studies are warranted to evaluate these and other assessments for neuropsychiatric symptoms of PICS across various diagnoses and conditions in ICU survivors.

Another area of continuing research is that of the post-ICU clinic in investigation of long-term outcomes of PICS, including long- term prevalence of neuropsychiatric symptoms, treatment strategies, mortality rates, readmission rates, financial impact for the healthcare system, and patient and caregiver satisfaction. These clinics allow for collaborative care not only in the areas covered in the Cleveland Clinic PIRC but also with geriatric medicine, otorhinolaryngology, endocrinology, nutrition, psychology, neuropsychiatry, and neuropsychology. Establishment of the post-ICU clinics allows clinicians and researchers to further investigate treatment modalities and prevention strategies and to improve care for ICU survivors.

\section{DISCLOSURES}

The authors report no relevant financial relationships which, in the context of their contributions, could be perceived as a potential conflict of interest.

\section{REFERENCES}

1. Society of Critical Care Medicine. Post-intensive care syndrome. https://www.sccm.org/MyICUCare/THRIVE/Post-intensive-Care-Syndrome. Accessed November 17, 2021.

2. Inoue S, Hatakeyama J, Kondo Y, et al. Post-intensive care syndrome: its pathophysiology, prevention, and future directions. Acute Med Surg 2019; 6(3):233-246. doi:10.1002/ams2.415

3. Needham DM, Davidson J, Cohen H, et al. Improving long-term outcomes after discharge from intensive care unit: report from a stakeholders conference. Crit Care Med 2012; 40(2):502-509. doi:10.1097/CCM.0b013e318232da75

4. Myers EA, Smith DA, Allen SR, Kaplan LJ. Post-ICU syndrome: rescuing the undiagnosed. JAAPA 2016; 29(4):34-37. doi:10.1097/01.JAA.0000481401.21841.32
5. Abate SM, Ahmed Ali S, Mantfardo B, Basu B. Rate of intensive care unit admission and outcomes among patients with coronavirus: a systematic review and meta-analysis. PLoS One 2020; 15(7):e0235653. doi:10.1371/journal.pone.0235653

6. Armstrong RA, Kane AD, Cook TM. Outcomes from intensive care in patients with COVID-19: a systematic review and meta-analysis of observational studies. Anaesthesia 2020; 75(10):1340-1349. doi:10.1111/anae.15201

7. Hermans G, Van den Berghe G. Clinical review: intensive care unit acquired weakness. Crit Care 2015; 19(1):274. doi:10.1186/s13054-015-0993-7

8. Mirzakhani H, Williams JN, Mello J, et al. Muscle weakness predicts pharyngeal dysfunction and symptomatic aspiration in longterm ventilated patients. Anesthesiology 2013; 119(2):389-397. doi:10.1097/ALN.0b013e31829373fe 
9. Cheung AM, Tansey CM, Tomlinson G, et al. Two-year outcomes, health care use, and costs of survivors of acute respiratory distress syndrome. Am J Respir Crit Care Med 2006; 174(5):538-544. doi:10.1164/rccm.200505-6930C

10. Fan E, Dowdy DW, Colantuoni E, et al. Physical complications in acute lung injury survivors: a two-year longitudinal prospective study. Crit Care Med 2014; 42(4):849-859. doi:10.1097/CCM.0000000000000040

11. Herridge MS, Tansey CM, Matté A, et al. Functional disability 5 years after acute respiratory distress syndrome. N Engl J Med 2011; 364(14):1293-1304. doi:10.1056/NEJMoa1011802

12. Sakusic A, Rabinstein AA. Cognitive outcomes after critical illness. Curr Opin Crit Care 2018; 24(5):410-414. doi:10.1097/MCC.0000000000000527

13. Ohtake PJ, Lee AC, Scott JC, et al. Physical impairments associated with post-intensive care syndrome: systematic review based on the World Health Organization's international classification of functioning, disability and health framework. Phys Ther 2018; 98(8):631-645. doi:10.1093/ptj/pzy059

14. Munn J, Willatts SM, Tooley MA. Health and activity after intensive care. Anaesthesia 1995; 50(12):1017-1021. doi:10.1111/j.1365-2044.1995.tb05942.x

15. Daffurn K, Bishop GF, Hillman KM, Bauman A. Problems following discharge after intensive care. Intensive Crit Care Nurs 1994; 10(4):244-251. doi:10.1016/0964-3397(94)90032-9

16. van der Schaaf M, Beelen A, Dongelmans DA, Vroom MB, Nollet F. Poor functional recovery after a critical illness: a longitudinal study. J Rehabil Med 2009; 41(13):1041-1048. doi:10.2340/16501977-0443

17. Poulsen JB, Møller K, Kehlet H, Perner A. Long-term physical outcome in patients with septic shock. Acta Anaesthesiol Scand 2009; 53(6):724-730. doi:10.1111/j.1399-6576.2009.01921.x

18. McHugh LG, Milberg JA, Whitcomb ME, Schoene RB, Maunder RJ, Hudson LD. Recovery of function in survivors of the acute respiratory distress syndrome. Am J Respir Crit Care Med 1994; 150(1): 90-94. doi:10.1164/ajrccm.150.1.8025779

19. Hopkins RO, Weaver LK, Collingridge D, Parkinson RB, Chan KJ, Orme JF Jr. Two-year cognitive, emotional, and quality-of-life outcomes in acute respiratory distress syndrome. Am J Respir Crit Care Med 2005; 171(4):340-347. doi:10.1164/rccm.200406-7630C

20. Pandharipande PP, Girard TD, Jackson JC, et al; BRAIN-ICU Study Investigators. Long-term cognitive impairment after critical illness. N Engl J Med 2013; 369(14):1306-1316. doi:10.1056/NEJMoa1301372

21. Gunther ML, Morandi A, Krauskopf E, et al. The association between brain volumes, delirium duration, and cognitive outcomes in intensive care unit survivors: the VISIONS cohort magnetic resonance imaging study. Crit Care Med 2012; 40(7):2022-2032. doi:10.1097/CCM.0b013e318250acc0

22. Garcez FB, Aliberti MJR, Poco PCE, et al. Delirium and adverse outcomes in hospitalized patients with COVID-19. J Am Geriatr Soc 2020; 68(11):2440-2446. doi:10.1111/jgs.16803

23. O'Hanlon S, Inouye SK. Delirium: a missing piece in the COVID-19 pandemic puzzle. Age Ageing 2020; 49(4):497-498. doi:10.1093/ageing/afaa094

24. Pun BT, Badenes R, Heras La Calle G, et al. Prevalence and risk factors for delirium in critically ill patients with COVID-19 (COVID-D): a multicentre cohort study. Lancet Respir Med 2021; 9(3):239-250. doi:10.1016/S2213-2600(20)30552-X

25. Helms J, Kremer S, Merdji H, et al. Delirium and encephalopathy in severe COVID-19: a cohort analysis of ICU patients. Crit Care 2020; 24(1):491. doi:10.1186/s13054-020-03200-1

26. Baller EB, Hogan CS, Fusunyan MA, et al. Neurocovid: pharmacological recommendations for delirium associated with COVID-19. Psychosomatics 2020; 61(6):585-596. doi:10.1016/j.psym.2020.05.013

27. Davidson JE, Harvey MA, Bemis-Dougherty A, Smith JM, Hopkins RO. Implementation of the Pain, Agitation, and Delirium Clinical Practice guidelines and promoting patient mobility to prevent postintensive care syndrome. Crit Care Med 2013; 41(9 suppl 1):S136S145. doi:10.1097/CCM.0b013e3182a24105

28. Marra A, Ely EW, Pandharipande PP, Patel MB. The ABCDEF bundle in critical care. Crit Care Clin 2017; 33(2):225-243. doi:10.1016/j.ccc.2016.12.005

29. Nikayin S, Rabiee A, Hashem MD, et al. Anxiety symptoms in survivors of critical illness: a systematic review and meta-analysis. Gen Hosp Psychiatry 2016; 43:23-29. doi:10.1016/j.genhosppsych.2016.08.005

30. Davydow DS, Hough CL, Zatzick D, Katon WJ. Psychiatric symptoms and acute care service utilization over the course of the year following medical-surgical ICU admission: a longitudinal investigation. Crit Care Med 2014; 42(12):2473-2481. doi:10.1097/CCM.0000000000000527

31. Jackson JC, Pandharipande PP, Girard TD, et al. Depression, posttraumatic stress disorder, and functional disability in survivors of critical illness in the BRAIN-ICU study: a longitudinal cohort study. Lancet Respir Med 2014; 2(5):369-379. doi:10.1016/S2213-2600(14)70051-7

32. Parker AM, Sricharoenchai T, Raparla S, Schneck KW, Bienvenu OJ, Needham DM. Posttraumatic stress disorder in critical illness survivors: a metaanalysis. Crit Care Med 2015; 43(5):1121-1129. doi:10.1097/CCM.0000000000000882

33. Davydow DS, Gifford JM, Desai SV, Needham DM, Bienvenu OJ. Posttraumatic stress disorder in general intensive care unit survivors: a systematic review. Gen Hosp Psychiatry 2008; 30(5):421-434. doi:10.1016/j.genhosppsych.2008.05.006

34. Bienvenu OJ, Gellar J, Althouse BM, et al. Post-traumatic stress disorder symptoms after acute lung injury: a 2-year prospective longitudinal study. Psychol Med 2013; 43(12):2657-2671. doi:10.1017/S0033291713000214

35. Patel MB, Jackson JC, Morandi A, et al. Incidence and risk factors for intensive care unit-related post-traumatic stress disorder in veterans and civilians. Am J Respir Crit Care Med 2016; 193(12):1373-1381. doi:10.1164/rccm.201506-11580C

36. Moss M, Bucher B, Moore FA, Moore EE, Parsons PE. The role of chronic alcohol abuse in the development of acute respiratory distress syndrome in adults. JAMA 1996;275(1):50-54. pmid:8531287

37. O'Brien JM Jr, Lu B, Ali NA, et al. Alcohol dependence is independently associated with sepsis, septic shock, and hospital mortality among adult intensive care unit patients. Crit Care Med 2007; 35(2):345-350. doi:10.1097/01.CCM.0000254340.91644.B2

38. Davydow DS, Zatzick D, Hough CL, Katon WJ. A longitudinal investigation of alcohol use over the course of the year following medical-surgical intensive care unit admission. Psychosomatics 2013; 54(4):307-316. doi:10.1016/j.psym.2013.01.003

39. Turnbull AE, Rabiee A, Davis WE, et al. Outcome measurement in ICU survivorship research from 1970 to 2013: a scoping review of 425 publications. Crit Care Med 2016; 44(7):1267-1277. doi:10.1097/CCM.0000000000001651

40. Needham DM, Sepulveda KA, Dinglas VD, et al. Core outcome measures for clinical research in acute respiratory failure survivors. An international modified Delphi consensus study. Am J Respir Crit Care Med 2017; 196(9):1122-1130. doi:10.1164/rccm.201702-0372OC

41. Stienen MN, Geisseler O, Velz J, et al. Influence of the intensive care unit environment on the reliability of the Montreal Cognitive Assessment. Front Neurol 2019; 10:734. doi:10.3389/fneur.2019.00734

42. Milani SA, Marsiske M, Cottler LB, Chen X, Striley CW. Optimal cutoffs for the Montreal Cognitive Assessment vary by race and ethnicity. Alzheimers Dement (Amst) 2018; 10:773-781. doi:10.1016/j.dadm.2018.09.003

43. Pfoh ER, Chan KS, Dinglas VD, et al. Cognitive screening among acute respiratory failure survivors: a cross-sectional evaluation of the Mini-Mental State Examination. Crit Care 2015; 19(1):220. doi:10.1186/s13054-015-0934-5

44. Honarmand K, Lalli RS, Priestap F, et al. Natural history of cognitive impairment in critical illness survivors. a systematic review. Am J Respir Crit Care Med 2020; 202(2):193-201. doi:10.1164/rccm.201904-0816Cl

45. Jutte JE, Needham DM, Pfoh ER, Bienvenu OJ. Psychometric evaluation of the Hospital Anxiety and Depression Scale 3 months after acute lung injury. J Crit Care 2015; 30(4):793-798. 
doi:10.1016/j.jcrc.2015.04.006

46. Bienvenu OJ, Williams JB, Yang A, Hopkins RO, Needham DM. Posttraumatic stress disorder in survivors of acute lung injury: evaluating the Impact of Event Scale-Revised. Chest 2013; 144(1):24-31. doi:10.1378/chest.12-0908

47. Hosey MM, Leoutsakos JS, Li X, et al. Screening for posttraumatic stress disorder in ARDS survivors: validation of the Impact of Event Scale-6 (IES-6). Crit Care 2019; 23(1):276. doi:10.1186/s13054-019-2553-z

48. Society of Critical Care Medicine. ICU Liberation Bundle (A-F). https://www.sccm.org/Clinical-Resources/ICULiberation-Home/ ABCDEF-Bundles. Accessed November 17, 2021.

49. Wergin R, Modrykamien A. Cognitive impairment in ICU survivors: assessment and therapy. Cleve Clin J Med 2012; 79(10):705-712. doi:10.3949/ccjm.79a.12038

50. Jackson JC, Ely EW, Morey MC, et al. Cognitive and physical rehabilitation of intensive care unit survivors: results of the RETURN randomized controlled pilot investigation. Crit Care Med 2012; 40(4):1088-1097. doi:10.1097/CCM.0b013e3182373115

51. Wilcox ME, Brummel NE, Archer K, Ely EW, Jackson JC, Hopkins RO. Cognitive dysfunction in ICU patients: risk factors, predictors, and rehabilitation interventions. Crit Care Med 2013; 41(9 suppl 1):S81S98. doi:10.1097/CCM.0b013e3182a16946

52. Kim YH, Ko MH, Na SY, Park SH, Kim KW. Effects of single-dose methylphenidate on cognitive performance in patients with traumatic brain injury: a double-blind placebo-controlled study. Clin Rehabil 2006; 20(1):24-30. doi:10.1191/0269215506cr927oa

53. Kim YW, Kim DY, Shin JC, Park Cl, Lee JD. The changes of cortical metabolism associated with the clinical response to donepezil therapy in traumatic brain injury. Clin Neuropharmacol 2009; 32(2):63-68. doi:10.1097/WNF.0B013E31816F1BC1
54. Zhang L, Plotkin RC, Wang G, Sandel ME, Lee S. Cholinergic augmentation with donepezil enhances recovery in short-term memory and sustained attention after traumatic brain injury. Arch Phys Med Rehabil 2004; 85(7):1050-1055. doi:10.1016/j.apmr.2003.10.014

55. Needham DM, Colantuoni E, Dinglas VD, et al. Rosuvastatin versus placebo for delirium in intensive care and subsequent cognitive impairment in patients with sepsis-associated acute respiratory distress syndrome: an ancillary study to a randomised controlled trial. Lancet Respir Med 2016; 4(3):203-212. doi:10.1016/S2213-2600(16)00005-9

56. Haerizadeh M, Sumner JA, Birk JL, et al. Interventions for posttraumatic stress disorder symptoms induced by medical events: a systematic review. J Psychosom Res 2020; 129:109908. doi:10.1016/j.jpsychores.2019.109908

57. Barreto BB, Luz M, Rios MNO, Lopes AA, Gusmao-Flores D. The impact of intensive care unit diaries on patients' and relatives' outcomes: a systematic review and meta-analysis. Crit Care 2019; 23(1):411. doi:10.1186/s13054-019-2678-0

58. Garrouste-Orgeas M, Flahault C, Vinatier I, et al. Effect of an ICU diary on posttraumatic stress disorder symptoms among patients receiving mechanical ventilation: a randomized clinical trial. JAMA 2019; 322(3):229-239. doi:10.1001/jama.2019.9058

59. Kredentser MS, Blouw M, Marten N, et al. Preventing posttraumatic stress in ICU survivors: a single-center pilot randomized controlled trial of ICU diaries and psychoeducation. Crit Care Med 2018; 46(12):1914-1922. doi:10.1097/CCM.0000000000003367

60. Teixeira C, Rosa RG. Post-intensive care outpatient clinic: is it feasible and effective? A literature review. Rev Bras Ter Intensiva 2018. 30(1):98-111. doi:10.5935/0103-507x.20180016

Address: Erin A. Dean, MD, Department of Psychiatry and Psychology, P57, Cleveland Clinic, 9500 Euclid Avenue, Cleveland, OH 44195; deane2@ccf.org 